\title{
Francis Limbach
}

\section{Gesamthand und Gesellschaft}

\author{
Geschichte einer Begegnung
}

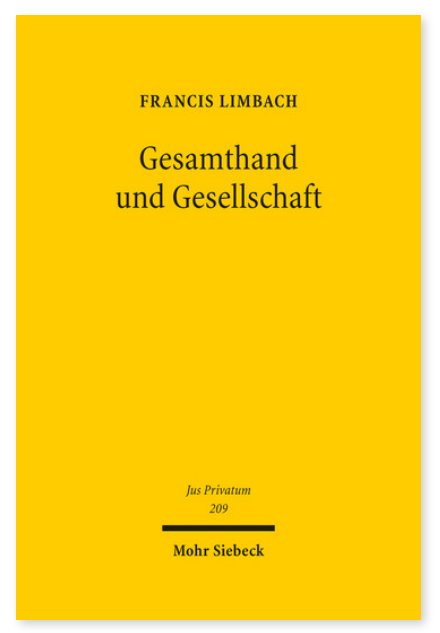

2016. XXVIII, 484 Seiten. JusPriv 209

ISBN 978-3-16-154177-3

DOI 10.1628/978-3-16-154177-3

eBook PDF 129,00€

ISBN 978-3-16-154176-6

Leinen $129,00 €$
Die besonderen Merkmale heutiger Gesamthandgemeinschaften sind auf den altdeutschen Gesamthandgedanken zurückzuführen - so die maßgeblich auf Gierke zurückgehende und auch heute verbreitete Vorstellung. Francis Limbach kommt hingegen zu dem Schluss, dass historische Gesamthandfiguren zwar existiert haben, ihre Rolle jedoch bei der Entwicklung des Gesellschaftsrechts vermutlich nicht prägend war. Vielmehr hat das Seehandelsrecht italienischer Stadtstaaten einen gesamteuropäischen Impuls für die Verselbständigung der Personengesellschaft gesetzt. So kam es erst vergleichsweise spät, nach Erschaffung der allgemeinen Gesamthanddogmatik im 19. Jahrhundert und am Vorabend der Kodifikation des deutschen Bürgerlichen Rechts, zu der »Begegnung« von Gesamthand und Gesellschaft. Francis Limbach zeichnet diese Entwicklung nach.

Francis Limbach Geboren 1970; Studium der Rechtswissenschaft in Saarbrücken, Freiburg und Toulouse; 2003 Promotion in Saarbrücken und Toulouse; 2002-04 Rechtsanwalt in einer internationalen Wirtschaftskanzlei in Frankfurt a. M.; seit 2004 Wissenschaftlicher Mitarbeiter an der Christian-Albrechts-Universität zu Kiel; 2015 Habilitation in Kiel; seit 2015 Privatdozent; im WS 2015/16 und im SS 2016 Lehrstuhlvertreter an der Ruprecht-Karls-Universität Heidelberg; seit WS 2016/17 Lehrstuhlvertreter an der Ludwig-Maximilians-Universität München.

Jetzt bestellen:

https://mohrsiebeck.com/buch/gesamthand-und-gesellschaft-9783161541773?no_cache=1

order@mohrsiebeck.com

Telefon: +49 (0)7071-923-17

Telefax: +49 (0)7071-51104 